Vol.3, No. 3, September 2021, pp. 141-151,doi.org:10.52567/pjsr.v3i3.235

www.pjsr.com.pk

\title{
LOCUS OF CONTROL, DELAY OF GRATIFICATION AND ADHERENCE TO TREATMENT IN PEOPLE WITH DIABETES
}

\author{
Musfirah Nasr Chaudhry \\ Lecturer, Department of Professional Psychology, \\ Bahria University (Lahore Campus), Pakistan \\ musfirahnasr93@gmail.com \\ Omama Tariq
Assistant Professor, Institute of Applied Psychology, \\ University of the Punjab, Lahore, Pakistan \\ omama.tariq.appsy@pu.edu.pk
}

\begin{abstract}
This study aims to explore the relationship among Locus of Control (LOC), Delay of gratification (DOG) and Adherence to treatment (ATT) in people living with type 2 diabetes (PLWT2D), who are overweight and normal weight. A sample of 100 PLWT2D, including 50 overweight (body mass index $\geq 23$ ) and 50 normal weight (body mass index=18.50-22.99), was recruited via purposive sampling technique. Delay of Gratification Inventory, Adult Nowicki-Strickland, Internal-External Control Scale and Summary of Diabetes Self-care Activities Measure were used. Pearson product-moment correlation, independent sample t-test and testing mediation with regression analysis were used for analysis. The results indicated that adherence to treatment and delay of gratification showed a negative relationship with locus of control while treatment adherence showed a positive relationship with delay of gratification. The results also showed that delay of gratification completely mediated the association between adherence to treatment and locus of control ( $p>.003$ ). There was no difference between locus of control, delay of gratification and adherence to treatment in overweight and normal-weight PLWT2D. The present study results would be beneficial for PLWT2D, counsellors, and doctors to help explore these factors while planning management and implementing them in daily life activities.
\end{abstract}

Keywords: Delay of gratification, Adherence to treatment, diabetes, Locus of control.

\section{INTRODUCTION}

Type 2 diabetes mellitus (T2DM) has become a growing concern in recent years because it has become the leading cause of disability and mortality (80\%) in comparison to other infectious diseases (WHO, 2009). Pakistan was reported to have 7.5 million cases of diabetes in 2017 (types 1 and 2) as pert the report of International Diabetes Federation (IDF). The IDF estimates that this will rise to 16.1 million by 2040 (International Diabetes Federation, 2017). According to recent survey by IDF in 2019, approximately 19 million individuals are living with diabetes in Pakistan. Out of these 19 million, 8.5 million are not diagnosed and have no knowledge about management of their disease which put them at risk for other health conditions (International Diabetes Federation, 2019). Aamir et al., (2019) reported that the prevalence of T2DM across Pakistan is $17 \%$ (community-based national study of 18,856 participants using HBA1c), and the rate of pre-diabetes is $10.91 \%$, which has increased more rapidly than expected. One of the reasons for the increase in cases of T2DM is a carbohydrate-rich diet and reduced level of physical activities (Arshad et al., 2016). Physical activity and diet are key to preventing and managing T2DM and its complications (International Diabetes Federation, 2009).

In modern times, fast food diet and reduced physical activity has led to cause different health conditions like diabetes and blood pressure. According to survey research, the incidence of diabetes in Pakistan is high: $12 \%$ of people above 25 years of age suffer from this condition, and $10 \%$ have impaired glucose tolerance (IGT). Approximately, 80 to 90 per cent of individuals with T2DM are also found having weight issues (Arshad et al. 2016; International Diabetes Federation, 2009). Recent facts showed 


\section{Chaudhry \& Tariq}

that $37 \%$ of men with diabetes and $79 \%$ of women with diabetes were overweight. The WHO has ranked Pakistan seventh in the diabetes pervasiveness list. The significant risk factors associated with diabetes were positive family history, age, and weight (The Nation, 2008; Sehra, Jawad \& Maqsood, 2007).

Weight problems in individuals are primarily due to their lack of control over diet and daily habits, which worsen their health, especially individuals with chronic illnesses, such as diabetes, heart, and liver problems. A study by Fuscaldi, Balsanelli and Grossi (2011) showed that LOC is significantly related to physical activity and diabetes, which can improve the health of PLWT2D. However, another research has also revealed that no significant link has found between self-management, familiarity with illness, health beliefs, and LOC (Joukar et al., 2013).

PLWT2D are likely to face issues while attempting to incorporate management and treatment into their daily lives. There are different factors that moderate management behaviors regarding diabetes (Delamater, 2006; Ansari, Dixon \& Browning, 2014). Different psychological factors can affect the management of PLWT2D and their reduced perception about lack of internal control over self-care behaviors (Shehnaz \& Tariq, 2010; Husnain, 2012).

Previous studies show a link between different physical problems and diabetes, which may result from the lack of control and non-delaying gratification attitude of the individuals (Nasim \& Kausar, 2014). Individuals who have a more significant locus of control (LOC) and delay of gratification (DOG) in their health-related attitude can see more improvements to their health. An individual with high locus of control and gratification delay may have good health because he or she is more likely to be receptive and perceptive to healthy cautionary actions (Carducci, 2009).

Another important factor which needs to be considered regarding the health of individuals with diabetes is their compliance and adherence with treatment as it contributes to their physical and psychological health. According to the bio-psychosocial model, some psychosocial factors affect adherence to treatment (ATT) in PLWT2D, such as stigmatization, identity issues, self-concept, achievement of the desired goals and control over behaviors. This model helps us understand that adherence can be affected by psychological and social factors, either internal or external, which affect attitudes towards daily life patterns. They may lead to a delay in engaging in self-management (Buchbinder et al., 2005). The bio-psychosocial model explains the influence of psychosocial factors on diabetes and these factors can include the control and delay in decisions related to health and disease. PLWT2D, who can follow the medical recommendations and change their lifestyles, can lead a longer and healthier life (Bilous, Donnelly \& Idris, 2021; WHO, 2015). This suggests that further research is needed to address risk factors to explore the factors that can act as enablers for PLWT2D in regard to the following recommendations.

The theoretical background and findings of previous international and indigenous studies suggest that delayed gratification and control are interlinked, and that internal control can predict and is positively correlated with ATT (Morowatisharifabad et al., 2010). Chew, Shariff-Ghazali and Fernandez (2014) showed that positive psychosocial factors are important mediators and independent predictors of clinical outcomes in chronic diabetes care. This means that positive psychological factors like DOG and selfefficacy can act as mediators and can predict impulses or LOC, which impact adherence. A study by Stupiansky et al. (2012) showed that impulse control was positively related to diabetes management; the higher the control, the better the disease management. It also showed that DOG behaviors such as resistance to food and financial spending related to health partially mediated the association between impulse control and diabetes management. These studies help us to understand the relationships among these factors and led us to study these problems in Pakistani society.

There is a need to explore the factors that may influence the adherence towards the recommended self-care behaviors for PLWT2D because South Asian countries like India and Pakistan's meal patterns or inactive lifestyles contradict with the recommended self-care behaviors. In south Asian countries like Pakistan, meals consist of a high intake of refined carbohydrates, such as white rice, which increases blood glucose levels. (Basit, Khan \& Khan, 2014; Basit et al. 2019). Other environmental factor that influence blood glucose levels is being less active and being overweight, especially central obesity. Making changes from their existing lifestyle can be challenging as different psychological factors may 
influence adherence of recommended self-care behaviors which may include existing control of their behaviors or needs. Hence, there is a need to explore factors that can have an influence on self-care behavior in PLWT2D.

The major factor that can affect the adherence and self-management in PLWT2D is lifestyle patterns, lack of control and delay in gratification is prominently a troublesome issue for most people in South-Asian communities as they do not start abstaining from unhealthy food until their condition gets serious (Jafar, Chaturvedi \& Pappas, 2006). Studying the lifestyle of people with diabetes is a topic which needs to be researched in the context of our national scenario. These factors like delaying attitude and lack of control in daily lives need improvement to control diabetes by enhancing adherence to medical recommendations. Therefore, relationship of locus of control, delay of gratification and adherence to treatment in current research was studied as it has fundamental implications for both research and clinical practice. To get better representation of the PLWT2D, individuals belong to different weight categories were taken. The mediating role of variables was studied depending on the previous studies (Chew, Shariff-Ghazali \& Fernandez, 2014; Stupiansky et al., 2012) due to which it was proposed that psychosocial factors like delay in gratification can act as mediator and can predict impulse or locus of control which exert impact on adherence.

It is thus hypothesized that;

- There is likely to be a relationship between delay of gratification, locus of control and adherence to treatment in people with type 2 diabetes.

- Delay of gratification is likely to mediate the relationship between locus of control and adherence to treatment in people with type 2 diabetes.

- There is likely to be a difference in variables of locus of control, delay of gratification and adherence to treatment in overweight and normal weight of people with type 2 diabetes.

\section{MATERIALS AND METHODS}

The study included administration and analysis of questionnaires in the native language of PLWT2D (Urdu). One hundred PLWT2D were recruited from three public hospitals using purposive sampling. Approval was granted from the hospitals.

\section{Participants}

Of the PLWT2D N=100 (50 overweight and 50 normal-weight individuals) were included. Criteria for participants were as follows: (1) Overweight and normal-weight individuals with diagnosed T2DM; overweight and normal-weight individuals were assessed through WHO classification of BMI; normalweight individuals had a BMI of 18.50 to 22.99, overweight individuals had a BMI of 23 or greater (WHO, 2015); (2) Individuals aged $\geq 25$, because according to the IDF, in Pakistan, diabetes is most prevalent in individuals aged around 25 to 30 (International Diabetes Federation, 2009). According to a survey of individuals aged above 25 years, $12 \%$ suffered from the condition, and $10 \%$ faced impaired glucose tolerance (Jawad, 2015); (3) Individuals on oral medication and who visited the hospital frequently for regular checkups; (4) Individuals with at least a primary level education to understand the concepts and statements in the questionnaires.

\section{Procedure}

Permission to use and translate the DOG, ATT and LOC scales was obtained through email from their respective authors. The scales were translated into Urdu according to the internationally accepted translation methodology of the MAPI guidelines. The scales were translated forward and backwards, and then pilot tested to obtain the final version. Letters of authorization from the relevant institute of the university explaining the nature of the research, signed by the research supervisor and the head of the institute were then taken to various hospitals. Three government hospitals agreed to provide data for the research. The next step was to approach participants. The purpose of the research was explained to potential participants, and the rapport was built to improve the quality of the results. Participants were provided informed consent before giving the questionnaires. The participants filled out the demographic 
information and the questionnaires according to our instructions. Participants were allowed to ask questions regarding the questionnaire.

\section{Measures \\ Delaying Gratification Inventory (Hoerger \& Weed, 2011)}

The Delaying Gratification Inventory developed by Michael Hoerger, Stuart W. Quirk and Nathan C. Weed (2011) was used to investigate the ability to delay (Hoerger \& Weed, 2011). The questionnaire consists of 35 items and five subscales: food, physical pleasure, social interaction, money management, and achievement. The subscale of physical pleasure was excluded from the current research because of cultural differences and irrelevance. The reverse-scored items of the remaining four subscales were $1,2,3,5,7,9,10,12,15,16,18,20,27$. Adding up the total score across all four subscales determined the total composite score. This total composite score determined an individual's DOG score (Hoerger \& Weed, 2011). The Cronbach alpha reliability of the scale in this research was .80 .

\section{Adult Nowicki-Strickland Internal-External Control Scale (Nowicki \& Duke, 1974)}

This scale was developed by Stephen Nowicki and Marshall Duke in 1974 and was used to identify the internal or external Locus of Control (LOC) (Nowicki \& Duke, 1974). The scale consists of 40 items. It is a dichotomous scale, where one has to reply either "yes" or "no" to 40 items. The Cronbach alpha reliability of the scale for the Urdu version in this research was .83 .

\section{Summary of Diabetes Self-Care Activity Measures (Toobert, Hampson \& Glascow, 2000)}

The Diabetes Self-Care Activity Measure helps indicating a patient's understanding of self-management goals and evaluate the correspondence between professed recommendations and reported levels of selfcare (Adherence) (Toobert, Hampson \& Glascow, 2000). This scale is a 25-item self-reporting measure of the frequency of diabetes and self-care tasks over the previous seven days. The measure is a short questionnaire that includes items assessing diabetes treatment: general diet, specific diet, exercise, blood glucose testing, foot care and smoking. The Cronbach alpha reliability of the scale in this research was .63.

\section{RESULTS}

Table 1: Correlation analysis showing relationship between LOC, DOG and ATT $(n=100)$

\begin{tabular}{|c|c|c|c|c|c|c|c|c|c|c|c|c|}
\hline Variable & 12 & 3 & 4 & 5 & 6 & 7 & 8 & 9 & 10 & 11 & 12 & 13 \\
\hline 1. ATT & $\begin{array}{l}.71 \\
* *\end{array}$ & $\begin{array}{l}.31 * \\
*\end{array}$ & $\begin{array}{l}.61 \\
* *\end{array}$ & $\begin{array}{l}.49 * \\
*\end{array}$ & $\begin{array}{l}.61 \\
* *\end{array}$ & $\begin{array}{l}.96^{*} \\
*\end{array}$ & $\begin{array}{l}- \\
.29 * \\
*\end{array}$ & $\begin{array}{l}.27 * \\
*\end{array}$ & .18 & $.24 *$ & .13 & $.25^{*}$ \\
\hline 2.GD & & $\begin{array}{l}.35^{*} \\
*\end{array}$ & $\begin{array}{l}.26 \\
* *\end{array}$ & $.23^{*}$ & $\begin{array}{l}.35 \\
* *\end{array}$ & $\begin{array}{l}.63^{*} \\
*\end{array}$ & $\begin{array}{l}- \\
.27 * \\
*\end{array}$ & $.24^{*}$ & .19 & .04 & $.23 *$ & $.21 *$ \\
\hline 3.SD & & & -.01 & -.07 & .10 & $\begin{array}{l}.26^{*} \\
*\end{array}$ & .03 & .12 & .17 & .15 & .10 & -.06 \\
\hline 4.exercise & & & & .15 & $\begin{array}{l}.30 \\
* *\end{array}$ & $\begin{array}{l}.55^{*} \\
*\end{array}$ & $-24 *$ & $\begin{array}{l}.33^{*} \\
*\end{array}$ & $\begin{array}{l}.28^{*} \\
*\end{array}$ & .12 & .19 & $.35 * *$ \\
\hline 5. BG & & & & & .06 & $\begin{array}{l}.40 * \\
*\end{array}$ & $.21 *$ & .02 & -.06 & .01 & -.04 & .07 \\
\hline 6.foot care & & & & & & $\begin{array}{l}.53 * \\
*\end{array}$ & $-25^{*}$ & $\begin{array}{l}.31^{*} \\
*\end{array}$ & .14 & $.38 * *$ & .11 & $.29 * *$ \\
\hline
\end{tabular}




\begin{tabular}{|c|c|c|c|c|c|c|}
\hline 7.smoking & $\begin{array}{l}- \\
.22 *\end{array}$ & .19 & .12 & .19 & .07 & .18 \\
\hline 8. LOC & & $\begin{array}{l}- \\
.52 * \\
*\end{array}$ & $\begin{array}{l}- \\
.40 * \\
*\end{array}$ & $-28 * *$ & $\begin{array}{l}- \\
.40 * \\
*\end{array}$ & $-.46^{* * *}$ \\
\hline 9. DOG & & & $\begin{array}{l}.71 * \\
*\end{array}$ & $.63 * *$ & $\begin{array}{l}.79 * \\
*\end{array}$ & $.74 * *$ \\
\hline 10.food & & & & $.26 * *$ & $\begin{array}{l}.47 * \\
*\end{array}$ & $.27 * *$ \\
\hline 11.social & & & & & $\begin{array}{l}.28^{*} \\
*\end{array}$ & $.31 * *$ \\
\hline 12.money & & & & & & $.44 * *$ \\
\hline
\end{tabular}

Note.*.p<.05; **. $\mathrm{p}<.01 ; * * * . \mathrm{p}<.001 ; \mathrm{ATT}=$ adherence to treatment; $\mathrm{GD}=$ general diet; $\mathrm{SD}=$ specific diet; $\mathrm{BG}=$ blood glucose level; $\mathrm{LOC}=$ locus of control; $\mathrm{DOG}=$ delay of gratification.

Table 2: Testing mediation with regression analysis showing the mediating role of DOG in the relationship between LOC and ATT $(n=100)$

\begin{tabular}{lll}
\hline Variable & \multicolumn{2}{l}{ ATT } \\
\cline { 2 - 3 } & $\Delta \mathrm{R}^{2}$ & $\mathrm{~B}$ \\
\hline Step 1 & $.09^{* *}$ & $47.06^{* * *}$ \\
Constant & & $-.48^{* *}$ \\
LOC & .02 & \\
Step 2 & & $31.51^{* *}$ \\
Constant & & -.34 \\
LOC & & .13 \\
DOG & .12 & \\
Step 3 & & $33.35^{*}$ \\
Constant & -.37 \\
LOC & .10 \\
DOG & .10 \\
Age & .66 \\
Education & -4.60 \\
Checking & .04 \\
BMI & &
\end{tabular}


Total $\mathrm{R}^{2}$ .22

Note. ${ }^{*} \mathrm{p}<.05 ;{ }^{* * *} \mathrm{p}<.01 ;{ }^{* * *} \mathrm{p}<.001 ; \beta=$ Standardized Coefficient; $\Delta \mathrm{R}^{2}=\mathrm{R}_{\text {Square change }} ; \mathrm{R}^{2}=\mathrm{R}_{\text {Square }}$

Table 3: Independent sample t test indicating differences in LOC, DOG and ATT among overweight and non-overweight people with diabetes $(n=100)$

\begin{tabular}{|c|c|c|c|c|c|c|c|c|c|}
\hline \multirow[b]{2}{*}{ Variables } & \multicolumn{2}{|c|}{$\begin{array}{l}\text { Normal weight } \\
(\mathrm{n}=50)\end{array}$} & \multicolumn{2}{|c|}{$\begin{array}{l}\text { Overweight } \\
(n=50)\end{array}$} & \multirow[b]{2}{*}{$t(98)$} & \multirow[b]{2}{*}{$p$} & \multicolumn{2}{|c|}{$95 \% \mathrm{CL}$} & \multirow[b]{2}{*}{ Cohen's d } \\
\hline & $M$ & $S D$ & $M$ & $S D$ & & & $L L$ & $U L$ & \\
\hline LOC & 38.80 & 13.20 & 38.57 & 13.13 & .27 & .61 & 3.29 & 5.20 & 0.02 \\
\hline DOG & 99.80 & 14.76 & 98.70 & 14.95 & .37 & .71 & -4.79 & 6.99 & 0.07 \\
\hline Food & 23.38 & 4.49 & 21.20 & 5.79 & 2.10 & .04 & .12 & 4.23 & 0.42 \\
\hline Social & 24.42 & 4.47 & 25.14 & 4.10 & -.84 & .40 & -2.42 & .98 & 0.17 \\
\hline Money & 26.58 & 5.68 & 26.24 & 5.50 & .30 & .76 & -1.88 & 2.56 & 0.06 \\
\hline Achievement & 25.42 & 5.38 & 26.12 & 5.40 & -.65 & .51 & -2.84 & 1.44 & 0.12 \\
\hline ATT & 39.62 & 11.97 & 37.90 & 12.17 & .71 & .48 & -3.07 & .65 & 0.14 \\
\hline GD & 4.15 & 2.08 & 3.88 & 1.96 & .67 & .51 & -.53 & 1.07 & 0.13 \\
\hline $\mathrm{SD}$ & 4.46 & 1.12 & 4.29 & 1.33 & .67 & .49 & -.32 & .66 & 0.13 \\
\hline Exercise & 3.60 & 1.97 & 2.71 & 2.00 & 2.26 & .03 & .11 & 1.66 & 0.44 \\
\hline BG & 3.73 & 2.51 & 3.03 & 2.27 & 1.46 & .15 & -.25 & 1.65 & 0.23 \\
\hline Foot care & 3.71 & 2.12 & 4.16 & 2.17 & -1.04 & .30 & -1.30 & .40 & 0.20 \\
\hline Smoking & 19.97 & 6.09 & 19.83 & 7.48 & .10 & .92 & -2.56 & 2.85 & 0.92 \\
\hline
\end{tabular}

Note. $\mathrm{CI}=$ confidence interval; $\mathrm{LL}=$ lower limit; $\mathrm{UL}=$ upper limit; $\mathrm{M}=$ mean; $\mathrm{SD}=$ standard deviation; $* \mathrm{p}<.05 ; \mathrm{DOG}=$ delay of gratification; $\mathrm{ATT}=$ adherence to treatment; $\mathrm{GD}=$ general diet; $\mathrm{SD}=$ specific diet; $\mathrm{BG}=$ blood glucose level.

The sample consisted of 50\% men and 50\% women. The mean age of participants was 44.75 and the mean years of education were 12.05. The average BMI was 26.75. Thirty-nine per cent of participants were employed, $58 \%$ were unemployed, and 5\% were retired. $81 \%$ of participants were married, and $19 \%$ were single. $68 \%$ had children between 0 and 3,28\% had between 4 and 7 children, and $4 \%$ had between 8 and 11 Children. $46 \%$ were living in a joint family system, and 54\% were living in a nuclear family system. $82 \%$ were living in urban areas, and $18 \%$ were living in rural areas. $40 \%$ reported that they check their sugar level daily, while $60 \%$ reported that they check their sugar level irregularly. 
Figure 1: Model depicting the mediating role of DOG between LOC and ATT

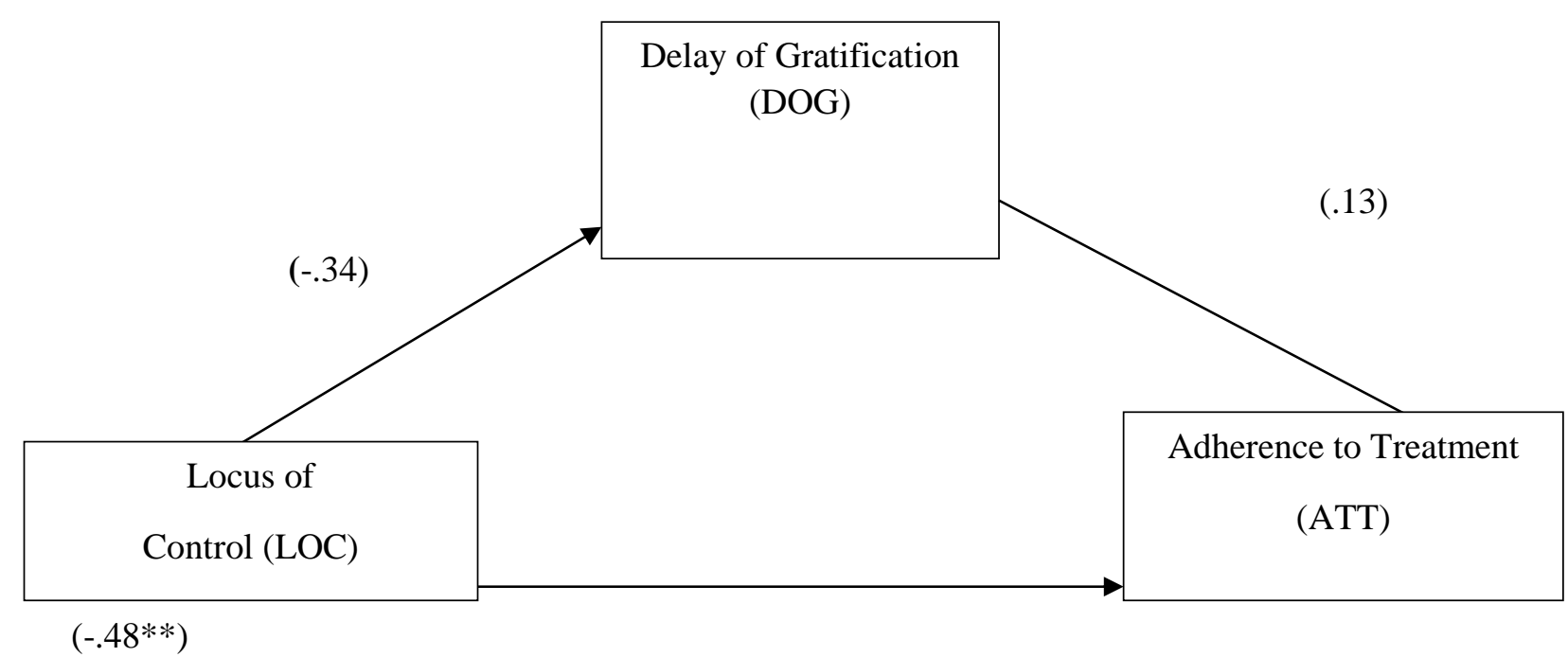

The relationship between study variables and their subscales can be seen in Table 1. For instance, ATT is negatively related to LOC and positively related to DOG, social gratification, and achievement gratification. The overall model of mediation (as seen in Table 2) explains $22 \%$ of the variance in adherence $F(9,90)=2.83, p<.006$, and indicates that there is no significant predictor of ATT. Model 2 shows a $.9 \%$ change in variance of adherence to treatment $F$ change $(2,97)=5.70, p<.005$, which indicates that LOC and DOG are non-significant predictors of ATT. Model 1 also shows $8.6 \%$ change in variance of adherence to treatment $F$ change $(1,98)=9.214 \mathrm{p}<.003$, which indicates that LOC is a significant predictor of ATT. Hence, the model indicates significance value for LOC decreases in the second model in the presence of a mediator. Hence, we can say that the model indicates the full mediation effect of DOG in relation to LOC and ATT (as seen in Figure 1). The test statistics value from the Sobel test is 2.54 , which is significant at .01. This also proved the mediation effect of DOG, in relation to LOC and ATT.

Table 3 shows that LOC, DOG and its subscales of social, money and achievement, and ATT and its subscales of general diet, specific diet, blood glucose level, foot care, and smoking were not significantly higher in normal-weight people compared to overweight people. However, the food subscale of DOG and the exercise subscale of ATT was significantly higher in normal-weight people compared to overweight people.

\section{DISCUSSION}

The present research examined the relationship between LOC, DOG and ATT. The results indicate that ATT and DOG have a negative relationship with LOC, while ATT has a positive relationship with DOG. This means that the higher the LOC, the lower the DOG. The negative correlation of LOC with DOG can be explained by a study that revealed that high LOC was associated with lower DOG because of the need for immediate reward, which can be seen in all individuals irrespective of the type of control (Janowski et al., 2013). It is also supported by a study which showed that psychological factors such as self-esteem, a delayed discounting attitude, altruistic behavior or pro-social behavior, and an ambitious attitude to obtain goals in life has been found to be associated with positive ATT (i.e., diet, foot care, exercise, medication) (Drotar, 2000). In a study conducted on the relationship between LOC and ATT, it was found that there was a negative association between ATT (i.e., diet, blood glucose monitoring, medication, foot care and exercise) and LOC (Morowatisharifabad et al., 2010). All these factors were observed in the current study, and participants responded in the same manner, with approximately the same deviations. 


\section{Chaudhry \& Tariq}

Individuals with more pro-social and empathetic behaviors were observed to have more adherence due to their positive attitude towards life, as they can control their desires for long-term rewards regarding their health. They are satisfied with their precautionary habits for diabetes prevention because, according to them, living a healthy life without any pleasure, such as food, is far more significant blessing compared to an unhealthy life with leisure. Individual delay in different perspectives of life regarding health and diet can help them attain a different level and type of adherence and act as an initiator of a healthy lifestyle.

It was hypothesized that DOG is likely to mediate the relationship between LOC and ATT. The results show a partial mediation of DOG between LOC and ATT. An earlier study showed that positive psychosocial factors are important mediators and independent predictors of clinical outcomes in chronic diabetes care (Chew, Shariff-Ghazali \& Fernandez, 2014). Positive psychological factors like DOG and self-efficacy can act as mediators and can predict impulses or control, which impact adherence. This correlates well with the current results. In ongoing research, if individuals can control behavior for longterm rewards, they are moving towards a high level of adherence, which will help them in achieving other gratifications in life, such as good health. Although living life with controlling diabetes and increasing intake of healthy food makes the individuals habitual of this lifestyle, and those who follow this pattern and don't deteriorate from it can easily lead a healthy lifestyle; but those who keep deteriorating their health usually always keep on striving to move towards the process of adherence, because for them health is the minor reinforcement. Therefore, if individuals want to live a healthy lifestyle with diabetes, they should follow this pattern of controlling and delaying moving towards adherence.

It was hypothesized that PLWT2D of normal weight are likely to have a higher LOC, DOG as compared to overweight people. The results showed no significant differences between the groups. Overweight and normal-weight people do not necessarily have differences in LOC, DOG regarding money, and social dimensions as these are individual psychological factors and have nothing to do with people's weight. Different factors like disease severity, lifestyle and emotional reactions can affect the psychological and physiological factors of individuals like internal control and delay in gratification rather than weight factor (Ajaml \& Ijaz, 2011). The present study also shows that the subscale of food was significantly higher in overweight people compared to normal-weight people (Tripathy et al., 2012). Weight increases in overweight individuals due to lack of exercise, which non-obese patients with diabetes more regularly perform; this correlates with the findings of Davis and Alonso (2004). Another study has shown that food is a significant reinforcement for overweight individuals, irrespective of whether they have diabetes or not (Epstein et al., 2010). This also shows that for future studies, there is a need to explore the possible reasons for barriers in making changes in diet and physical activity and difficulties in DOG in this regard for PLWT2D in Pakistan.

It was hypothesized that people with diabetes of normal weight are likely to have higher ATT than overweigh people with diabetes. The present study shows that ATT and its dimensions of general diet, specific diet, blood glucose level, foot care and smoking showed no differences between overweight and normal-weight people. One of the reasons for this could be that adherence cannot be determined differently in overweight and normal-weight people, as both showed adherence to some extent (regarding diet, foot care, smoking, medication, blood glucose). A study by New et al. (2000) showed that both overweight and normal-weight individuals with PLWT2D did not show any adherence to Diabetes on all its dimensions as both have their factors of family and income, which can affect the treatment. The current study results also show that exercise was significantly higher in normal-weight PLWT2D as compared to overweight PLWT2D. This keeps the former in the category of normal weight individuals due to their healthy physical habits.

\section{CONCLUSION}

The present study results show that ATT has a negative relationship with LOC and a positive relationship with DOG. There is a negative association between LOC and DOG. The mediation analysis shows that DOG mediates the relationship between LOC and ATT among overweight and normal-weight PLWT2D. Overweight and normal-weight people showed no significant differences in DOG and ATT. 


\section{LIMITATIONS AND SUGGESTIONS}

The data was collected from only three government hospitals, so it is not enough to provide a representation of the people of Pakistan as a whole. Therefore, it is recommended that more data should be collected from the hospitals to generalize it throughout Pakistan. Hospitals located in other cities should be included in the sample, and private hospitals should also be considered. Different factors like socio-economic statuses should also be discussed in future researches as two-thirds of the population of Pakistan belongs to the middle and lower socio-economic class, who visit government hospitals. Therefore, we can say that his finding needs further exploration considering different factors to be generalized.

\section{IMPLICATIONS}

- The findings have implications for health psychologists, doctors, counsellors, and other healthcare professionals because people with diabetes suffer from psychological problems like depression and need counselling.

- These findings will be helpful for family members in understanding the emotions and problems of people living with diabetes.

- The findings will help doctors understand the severity of the disease by knowing the physical factors of adherence and control levels and will help them advise people about their problems accordingly.

- Health psychologists and counsellors can play an essential role in addressing, guiding, and satisfying the psychological needs of people by understanding the factors studied here, which will help people reduce their mental distress and other psychological issues.

- This research addresses the psychological factors which most PLWT2D face in their lives, such as levels of adherence to recommendations. Therefore, it can guide future researchers in

Declarations exploring ATT, LOC, and DOG in people with other illnesses.

\section{Funding}

No funding was received for conducting this study.

\section{Conflict of Interest}

All authors declare no conflict of interest.

\section{Ethical Standards}

Permission was obtained through email from the authors of the delaying gratification inventory, adherence to treatment scale and locus of control scale for translation and usage purposes. Permission letters were obtained from the academic institutes and were signed by concerned authorities in the hospitals. Each participant signed an informed consent form, and participants' information was kept confidential. The questionnaire was only presented to individuals who met the research criteria. Assurance was provided to participants regarding information privacy and that the results would not be used for any purpose other than research.

\section{REFERENCES}

Aamir, A.H., Ul-Haq, Z., Mahar, S.A., Qureshi, F.M., Ahmad, I., Jawa, A., Sheikh, A., Raza, A., Fazid, S., Jadoon, Z., Ishtiaq, O., Safdar, N., Afridi, H., \& Heald, A.H. (2019). Diabetes Prevalence Survey of Pakistan (DPS-PAK): prevalence of type 2 diabetes mellitus and prediabetes using HbA1c: a population-based survey from Pakistan. BMJ Open, 9(2).

Ajmal, M.A., \& Ijaz, S. (2011). Experiencing Type II Diabetes in Pakistan. Pakistan Journal of Social and Clinical Psychology, 9, 50-56. 
Ansari, R.M., Dixon, J.B., \& Browning, C.J. (2014). Self-Management of Type 2 Diabetes in a MiddleAged Population of Pakistan and Saudi Arabia. Open Journal of Preventive Medicine, 4(1), 396-407.

Arshad, R., Younis, B.B., Masood, J., Tahira, M., \& Khurshid, S. (2016). Pattern of physical activity among persons with type 2 diabetes with special consideration to daily routine. Pakistan Journal of Medical Sciences, 32(1).

Basit, A., Fawwad, A., Ali Siddiqui, S., \& Baqa, K. (2019). Current management strategies to target the increasing incidence of diabetes within Pakistan [Corrigendum]. Diabetes, Metabolic Syndrome and Obesity: Targets and Therapy, 12, 851-852.

Basit, A., Khan, A., \& Khan, R.A. (2014). Bright guidelines on self-monitoring of blood glucose. Pakistan Journal of Medical Sciences, 30(5), 1150-1155.

Bilous, R.W., Donnelly, R., \& Williams, G. (2021). Handbook of Diabetes. Wiley-Blackwell.

Buchbinder, M.H., Detzer, M.J., Welsch, R.L., Christiano, A.S., Patashnick, J.L., \& Rich. M. (2005). Assessing Adolescents with Insulin-Dependent Diabetes Mellitus: A Multiple Perspective Pilot Study Using Visual Illness Narratives and Interviews. Journal of Adolescent Health, $6(1), 9-13$

Carducci, B.J. (2009). The psychology of personality: viewpoints, research, and applications ( $2^{\text {nd }}$ ed.).

Wiley Blackwell.

Chew, B.H., Shariff-Ghazali, S., \& Fernandez, A. (2014). Psychological Aspects of Diabetes Care: Effecting Behavioral Change in People. World Journal of Diabetes, 5(6), 796-808.

Davis, S., \& Alonso, M.D. (2004). Hypoglycemia as a barrier to glycemic control. Journal: of Diabetes Complications, 18(1), 60-8.

Delamater, A.M. (2006). Improving Patient Adherence. Clinical Diabetes, 24(2), 71-77.

Drotar, D. (2000). Promoting Adherence to Medical Treatment in Chronic Childhood Illness: Concepts, Methods, and Interventions. Lawrence Erlbaum Associates.

Epstein, L.H., Salvy, S.J., Carr, K.A., Dearing, K. K., \& Bickel, W.K. (2010). Food Reinforcement, Delay Discounting and Obesity. Physiology \& Behavior, 100 (5), 438-445.

Fuscaldi, F.S., Balsanelli, A.C.S., \& Grossi, S.A.A. (2001). Locus of Control in Health and Self-Esteem in Type-2 Diabetic Patients. Revista da Escola de Enfermagem da USP, 45(4), 855-861.

Hoerger, M., \& Weed, N.C. Development and Validation of the Delaying Gratification Inventory. Psychological Assessment, 23(3), 725-738

Husain, N. (2012). Psychosocial Correlation between Diabetes Mellitus and Depression: A Primary Care Study from a Low Country. Chujal Medical, 85(1), 62-65.

International Diabetes Federation. (2009) Asthma, Obesity and Type 2 Diabetes - Mechanisms, Management and Prevention. Retrieved from; http://www.idf.org/diabetesvoice/articles/asthmaobesity-and-type-2-diabetes-mechanisms-management-and-prevention

International Diabetes Federation. (2017). Diabetes Atlas - Home. Retrieved from; http://www.diabetesatlas.org/.

International Diabetes Federation. (2019). Diabetes Atlas - Home. Retrieved from https://diabetesatlas.org/en/

Jafar, T.H., Chaturvedi, N., \& Pappas, G. (2006). Prevalence of overweight and obesity and their association with hypertension and diabetes mellitus in an Indo-Asian population. CMAJ, 175(9), 1071-1077.

Janowski, K., Kurpas, D., Kusz, J., Mroczek, B., \& Jedynak, T. (2013). Health-Related Behavior, Profile of Health Locus of Control and Acceptance of Illness in People Suffering from Chronic Somatic Diseases. PLoS One, 8(1), 1-7.

Jawad, F. (2015). Diabetes in Pakistan. Diabetes Voice, 48(2), 12-14.

Joukar, F, Mansour-Ghanaei, R., Soati, F., \& Khanegha, A.G. (2013). Association between Knowledge, Locus of Control and Health Belief with Self-Management, Hb A1C Level and Number of Attendances in Type 1 Diabetes Mellitus People. International Journal of Clinical and Experimental Medicine, 6(6), 470-477. 
Morowatisharifabad, M.A., Mahmoodabad, S.S.A., Baghianimoghadam, M.H., \& Tonekaboni, N.R. (2010). Relationships between Locus of Control and Adherence to Diabetes Regimen in a Sample of Iranians. International Journal of Diabetes in Developing Countries, 30(1), 27-32.

Nasim, F., \& Kausar, R. (2014). Locus of Control, Treatment Motivation, Diabetic Care and Medication Adherence in People with Diabetes Type-II [Unpublished thesis, Institute of Applied Psychology, University of the Punjab].

New, J.P., Hollis, S., Campbell, F., McDowell, D., Burns, E., \& Dornan, T.L., \& Young, R. J. (2004). Measuring Clinical Performance and Outcomes from Diabetes Information Systems: An Observational Study. Diabetologia, 43(7), 836-843.

Nowicki, S., \& Duke, M. (1974). A Locus of Control Scale for Non-college as Well as College Adults. Journal of Personality Assessment, 38, 136-137.

Sehra, A.S., Jawad, F., \& Maqsood, A. (2007). Prevalence of Diabetes in Pakistan. Diabetes Research and Clinical Practice, 6(2), 219-222.

Shehnaz, S., \& Tariq, O. (2010). Body Mass Index, Depression and Adherence in Adults with Type II Diabetes. [Unpublished master's thesis, Institute of Applied Psychology, University of the Punjab]

Stupiansky, N.W., Hanna, K.M., Slaven, J.E, Weaver, M.T, \& Fortenberry, J.D. (2013). Impulse control, diabetes-specific self-efficacy, and diabetes management among emerging adults with type 1 diabetes. Journal of pediatric psychology, 38(3), 247-254.

The Nation. (2008). WHO ranks Pakistan 7th on diabetes list. The Nation.

Toobert, D.J, Hampson, S.E, \& Glascow, R.E. (2000). The Summary of Diabetes Self-Care Activities Measure. Diabetes Care, 23(7), 943-950.

Tripathy, B.B., Hemraj, B., Das, A.K. \& Rao, P.V. (2012). RSSDI Textbook of Diabetes Mellitus. Jaypee Brothers' Medical Publishers.

World Health Organization. (2015). Obesity and Overweight. Retrieved from; http://www.whoint/mediacentre/factsheets/fs311/en/

World Health Organizations. (2019). Deaths from NCDs: World Health Organization. Retrieved from; https://www.who.int/gho/ncd/mortality_morbidity/ncd_total_text/en/ 